\title{
Caesalpinioideae (Leguminosae) nos Campos Rupestres do Parque Estadual do Itacolomi, MG, Brasil ${ }^{1}$
}

\author{
Valquíria Ferreira Dutra ${ }^{2,4}$, Flávia Cristina Pinto Garcia e Haroldo Cavalcante de Lima ${ }^{3}$
}

Recebido em 6/03/2007. Aceito em 13/08/2007

\begin{abstract}
RESUMO - (Caesalpinioideae (Leguminosae) nos Campos Rupestres do Parque Estadual do Itacolomi, MG, Brasil). Este trabalho consiste do estudo florístico de Caesalpinioideae dos Campos Rupestres do Parque Estadual do Itacolomi (PEI), localizado no sul da Cadeia do Espinhaço. As coletas foram mensais, no período entre setembro/2003 e outubro/2004. Foram encontradas 13 espécies de Caesalpinioideae, reunidas em três gêneros: Bauhinia, Chamaecrista e Senna. O gênero Chamaecrista foi o que mais se destacou em número de espécies. Foram elaboradas chaves para identificação das espécies, além de diagnoses, ilustrações e comentários sobre afinidades, distribuição geográfica e fenologia das mesmas.
\end{abstract}

Palavras-chave: Leguminosae, Caesalpinioideae, Parque Estadual do Itacolomi, Campos Rupestres

ABSTRACT - (Caesalpinioideae (Leguminosae) in "Campos Rupestres" of Itacolomi State Park, Minas Gerais State, Brazil). This work consists of a floristic study of the Caesalpinioideae in "Campos Rupestres" at Itacolomi State Park, southern Espinhaço Range. Collections were carried out monthly from September 2003 to October 2004. Thirteen species of Caesalpinioideae belonging to three genera were found: Bauhinia, Chamaecrista and Senna. The genus Chamaecrista had the highest number of species. Species identification keys are presented, as well as descriptions, illustrations and comments on morphological relationships, geographic distribution and phenology.

Key words: Leguminosae, Caesalpinioideae, Itacolomi State Park, "Campos Rupestres”

\section{Introdução}

Leguminosae Adans. é constituída de 730 gêneros e 19.325 espécies, e é subdividida em três subfamílias: Caesalpinioideae, Mimosoideae e Papilionoideae (Lewis et al. 2005), situando-se entre as três maiores famílias de Angiospermae (Polhill et al. 1981). Apresenta hábito variado, desde ervas perenes até árvores de grande porte, folhas, em geral, compostas, inflorescência racemosa, flores com corola dialipétala e zigomorfa, com exceção das Mimosoideae, que possuem corola gamopétala, de simetria radiada, frutos do tipo legume e suas variações, como legume bacóide, nucóide e samaróide, lomento, folículo, sâmara e drupa (Barroso et al. 1991; Barroso et al. 1999). O monofiletismo da família foi confirmado por Chappill (1995) e Doyle et al. (2000), pela presença de folhas compostas, com pulvinos e de uma pétala adaxial diferenciada, ovário monocarpelar e frutos do tipo legume. A família consiste no elemento principal de muitos tipos vegetacionais (Lewis 1987), sendo encontrados, no Brasil, cerca de 178 gêneros e 3.170 espécies (Barroso et al. 1991). Nos Campos Rupestres encontra-se bem representada, com cerca de 338 espécies, reunidas em 52 gêneros (Garcia \& Dutra 2004).

Caesalpinioideae compreende 171 gêneros e 2.250 espécies (Lewis et al. 2005), abundantes na América do Sul, África tropical e sudeste da Ásia (Cowan 1981). Segundo Barroso et al. (1991), as espécies nativas correspondem a 64 gêneros e 790 espécies. Nos Campos Rupestres a subfamília está representada por sete gêneros e 94 espécies (Garcia \& Dutra 2004). Distingue-se pelas folhas pinadas ou bipinadas, raramente simples ou 1-folioladas; flores geralmente zigomorfas, 4-5-meras, com sépalas livres (exceto em Cercideae), sendo a pétala adaxial sobreposta pelas pétalas laterais adjacentes, quando estas estão presentes; o legume é o tipo de fruto mais freqüente e as sementes não apresentam ranhura hilar e geralmente possuem o eixo da radícula reto (Cowan 1981; Barroso et al. 1999).

\footnotetext{
1 Parte da Dissertação de Mestrado da primeira Autora

2 Universidade Federal de Viçosa, Departamento de Biologia Vegetal, Av. Peter Henry Rolfs s.n., Campus Universitário, 36570-000 Viçosa, MG, Brasil

3 Instituto de Pesquisas Jardim Botânico do Rio de Janeiro, Rua Pacheco Leão 915, 22460-030 Rio de Janeiro, RJ, Brasil

4 Autor para correspondência: valquiria.dutra@bol.com.br
} 
O Parque Estadual do Itacolomi (PEI) situa-se na porção sul da Cadeia do Espinhaço (Peron 1989), região de extrema importância biológica (Drummond et al. 2005). Sua vegetação é classificada, na maior parte, como Campo Rupestre, que ocorre em altitudes superiores a $900 \mathrm{~m}$. Estudos envolvendo a família no PEI restringem-se à listagem preliminar das fanerógamas do Parque, realizada por Peron (1989) e ao levantamento florístico de Messias et al. (1997). Dutra et al. (2005) estudaram as Papilionoideae dos Campos Ferruginosos do PEI e Lima et al. (2007) realizaram o estudo da família para as Florestas Estacionais Semideciduais do Parque.

O presente trabalho visou o inventário florístico das Caesalpinioideae ocorrentes nos Campos Rupestres do PEI, com a elaboração de chaves analíticas, diagnoses e ilustrações para a identificação dos gêneros e espécies estudados, bem como comentários sobre a morfologia, a distribuição geográfica e a fenologia das mesmas.

\section{Material e métodos}

O Parque Estadual do Itacolomi (PEI) localiza-se nos municípios de Ouro Preto e Mariana (Fig. 1A), Estado de Minas Gerais (20²2'30' 20³0'00'S e $\left.43^{\circ} 32^{\prime} 30^{\prime}, 43^{\circ} 22^{\prime} 30^{\prime}, \mathrm{W}\right)$. Ocupa uma área de aproximadamente 7.000 ha, sendo o ponto mais elevado o Pico do Itacolomi, com 1.772 m (Messias et al. 1997). Localiza-se no extremo oeste da região da Mata Atlântica, ocupando a zona de transição entre ela e o Cerrado, sendo sua vegetação composta por Floresta Estacional Semidecidual e Campos Rupestres (Messias et al. 1997). Estes abrangem toda a área acima da cota de $900 \mathrm{~m}$, onde se podem identificar seis tipos básicos de formações vegetacionais: os campos graminosos secos, formados por um estrato graminóide e por arbustos esparsos; os campos graminosos úmidos, associados às áreas aplainadas, de menores altitudes e constantemente alagadas e que apresentam um estrato graminóide desenvolvido, além de numerosos arbustos e subarbustos; os campos graminosos úmidos de altitude, também associados a áreas aplainadas e de solos encharcados, caracterizados por um estrato graminóide contínuo; campos quartzíticos dos afloramentos rochosos, formados pela vegetação rupícula; os campos ferruginosos, ambientes rúpicolas que apresentam subarbustos e arbustos se desenvolvendo sobre concreções ferruginosas; e os escrubes, caracterizados pela presença de numerosos subarbustos e arbustos e de um estrato graminóide pouco desenvolvido (Dutra 2005).

Foram realizadas, mensalmente, visitas ao PEI, no período de setembro/2003 a outubro/2004, ao longo de trilhas e das estradas do Parque (Fig. 1B), abrangendo toda a variação fitofisionômica encontrada (Estrada de Cima, Estrada de Baixo, Morro do Cachorro, Baú, Calais, Tesoureiro, Serrinha e Sertão). Depois de coletado, o material foi herborizado e registrado no acervo do Herbário VIC, do Departamento de Biologia Vegetal da Universidade Federal de Viçosa. Duplicatas foram enviadas aos Herbários OUPR, da Universidade Federal de Ouro Preto e RB, do Jardim Botânico do Rio de Janeiro.

Adotou-se o sistema de classificação de Polhill (1994) para os táxons supragenéricos. A nomenclatura morfológica usada nas diagnoses foi baseada nos trabalhos de Radford et al. (1974), Polhill \& Raven (1981) e Barroso et al. (1999). As diagnoses genéricas basearam-se na amplitude de variação do táxon extraída da literatura e as diagnoses específicas ou infra-específicas na amplitude de variações morfológicas observadas no material coletado no PEI, sendo estas dispostas em ordem alfabética no texto. Comentários sobre a distribuição geográfica, obtida na literatura, a ocorrência das espécies nas trilhas percorridas, os limites taxonômicos específicos e a fenologia são fornecidos após a descrição de cada táxon, específico ou infra-específico. A chave para identificação dos táxons foi elaborada com base nos caracteres vegetativos e reprodutivos do material coletado no PEI e as ilustrações foram confeccionadas com o auxílio de um estereomicroscópio e incluíram o aspecto geral do ramo e partes reprodutivas utilizadas no reconhecimento dos táxons, sendo utilizados materiais herborizados e/ou fixados em álcool $70 \%$.

\section{Resultados e discussão}

Nos Campos Rupestres do Parque Estadual do Itacolomi, a família Leguminosae está representada por 52 espécies, reunidas em 24 gêneros, agrupados em 12 tribos (Dutra 2005), ou seja, aproximadamente $15 \%$ das espécies de Leguminosae citadas para a flora dos Campos Rupestres do Brasil, segundo Garcia \& Dutra (2004).

Caesalpinioideae é a segunda maior subfamília na área, com 13 espécies, reunidas em três gêneros e duas tribos, Cercideae e Cassieae. O gênero mais representativo em número de espécies é Chamaecrista, seguido por Senna e Bauhinia. Este resultado confirma o encontrado por Garcia \& Dutra 

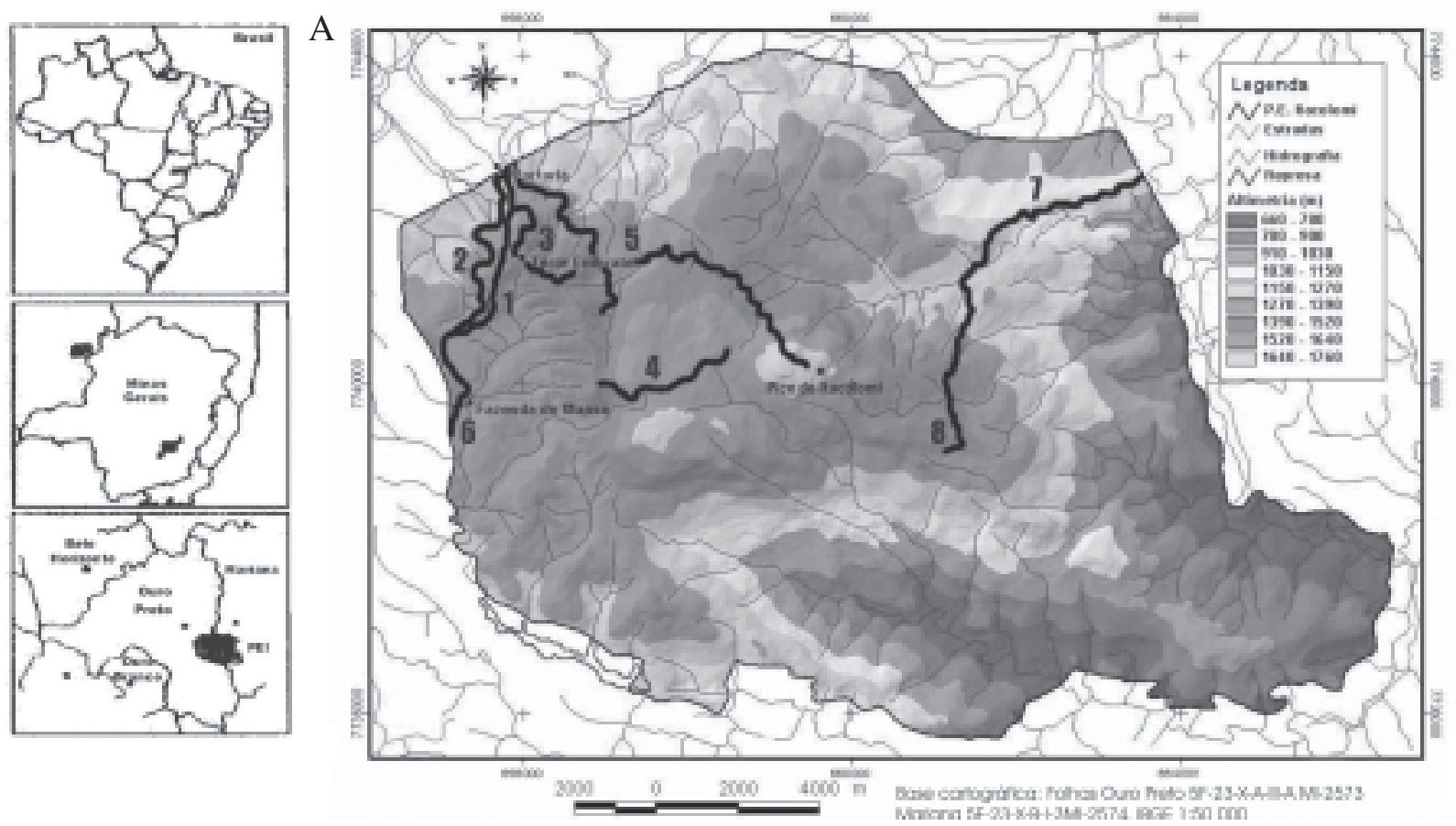

Figura 1. A. Localização do Parque Estadual do Itacolomi, MG, Brasil. B. Trilhas estudadas. 1. Estrada de Cima; 2. Estrada de Baixo; 3. Morro do Cachorro; 4. Baú; 5. Calais; 6. Tesoureiro; 7. Serrinha; 8. Sertão.

(2004), que citam o gênero Chamaecrista como o mais bem representado nos Campos Rupestres.

No PEI as espécies dessa subfamília apresentam hábito herbáceo, subarbustivo ou arbustivo, folhas unifolioladas ou paripinadas que, em algumas espécies têm nectários foliares, flores zigomorfas ou assimétricas, com pétalas amarelas ou brancas, livres e legumes plano-compressos ou subcilíndricos.

Chave para os gêneros de Caesalpinioideae dos Campos Rupestres do Parque Estadual do Itacolomi

1. Folhas unifolioladas ou aparentemente simples, bilobadas; cálice gamossépalo; pétalas brancas 1. Bauhinia

1. Folhas 2-36-folioladas; cálice dialissépalo; pétalas amarelas

2. Nectário foliar pateliforme ou ausente; corola assimétrica; estames 5 ou 10 férteis, subisomórficos; legume elasticamente deiscente 2. Chamaecrista

2. Nectário foliar piriforme, globoso ou claviforme; corola zigomorfa; estames 6 ou 7 férteis, heteromórficos, 2-3 abaxiais longos e 4 medianos; legume indeiscente ou com deiscência passiva .

\section{Bauhinia L., Sp. Pl. 1: 374. 1753.}

Arbustos, eretos ou escandentes, árvores ou lianas. Folhas unifolioladas ou aparentemente simples, inteiras a bilobadas, bipartidas até distintamente bifolioladas; estípulas decíduas ou persistentes; nectários foliares intra-estipulares, obsoletos ou ausentes. Inflorescência pseudoracemosa ou paniculada, supra-axilar, subopositifolia ou terminal; flores 5-meras, zigomorfas; cálice gamossépalo, tubuloso ou globoso; pétalas brancas ou róseas; estames 10, filetes longos, livres ou irregularmente unidos na base formando uma coluna, anteras rimosas; 1-9 estaminódios; ovário estipitado ou subséssil, estilete reto ou curvado, estigma oblíquo ou terminal, peltado, bilobado, clavado, capitado ou dilatado. Fruto do tipo legume, com deiscência elástica ou indeiscente.

\subsection{Bauhinia ungulata L. var. cuiabensis (Bong.)} Vaz, Rodriguésia 54(83): 125. 2003.

Pauletia cuyabensis Bong., Mem. Acad. Imp. Sci.

St. Petersb., ser. 4 sci. Math. 2: 125. 1836.

Fig. 2-4

Arbustos 2-4 m alt., ramos estriados, ferrugíneopuberulentos. Folhas unifolioladas, bilobadas, 1,2-3,3×2,2-5,8 cm, 9-11-nervadas; estípulas ca. $2 \mathrm{~mm}$ compr., lanceoladas; folíolos divididos de um terço à metade, lobos sub-reniformes a elípticos, margem 
inteira, face abaxial puberulenta, com tricomas glandulares, face adaxial glabra; nectário rudimentar. Inflorescência pseudoracemosa, pluriflora, terminal; cálice 5-9,3 cm compr., tubuloso, ferrugíneo, puberulento externamente; corola 2,3-3,8 cm compr., pétalas brancas, linear-lanceoladas; estames heterodínamos, 3,8-6 cm compr., filetes irregularmente unidos na base formando uma coluna, anteras 0,8-1,2 cm compr.; estaminódios ausentes; ovário ca. 1,5 cm compr., estipitado, puberulento, estilete ca. $3,3 \mathrm{~cm}$ compr., glabro, estigma oblíquo, clavado. Legume planocompresso, 13-15,5×1,5 cm, apiculado, puberulento; 9-14 sementes, $1 \times 0,5 \mathrm{~cm}$, obovadas, esverdeadas.

Material examinado: BRASIL. Minas Gerais: PEI, Mariana, Serrinha, 30/IX/2003, fr., Dutra et al. 131 (VIC); 13/IV/2004, fl. fr., Dutra \& Garcia 217 (VIC); 13/IV/2004, fl., Dutra \& Garcia 218 (VIC); 13/IV/2004, fl., Dutra \& Garcia 220 (VIC); 4/VIII/2004, fr., Dutra et al. 263 (VIC).

Bauhinia ungulata var. cuiabensis ocorre no Paraguai e no Brasil, nos Estados da Bahia, Goiás, Mato Grosso, Mato Grosso do Sul, Minas Gerais, Rio de Janeiro, São Paulo, Tocantins e no Distrito Federal, habitando florestas, cerrados, campos, em formações do pantanal, carrascos e caatingas (Vaz \& Tozzi 2003). No PEI é muito frequiente nos campos graminosos úmidos da Serrinha.
Floração: de abril a agosto. Frutificação: de julho a outubro.

Segundo Vaz \& Tozzi (2003), B. ungulata é altamente variável, mas com padrões locais que suportam o reconhecimento de quatro variedades. Os principais caracteres diagnósticos de B. ungulata var. cuiabensis, observados no material examinado, são as pétalas linear-lanceoladas e as folhas unifolioladas, 9-11-nervadas, divididas de um terço à metade de seu comprimento.

\section{Chamaecrista Moench, Methodus 272. 1794.}

Ervas, subarbustos, arbustos ou árvores. Folhas paripinadas, 2-plurifolioladas; estípulas geralmente persistentes; nectário foliar, quando presente, pateliforme, secretando néctar em uma superfície côncava. Inflorescência racemosa, axilar, supra-axilar ou cauliflora; flores 5-meras, assimétricas; cálice dialissépalo; corola amarela, pétala abaxial interna às vezes diferenciada (cuculada, falcada ou encurvada sobre os estames); estames 5 a 10, subisomórficos, isto é, diferindo pouco em tamanho, os do verticilo externo levemente maiores, filetes livres não excedendo metade do comprimento das anteras, anteras poricidas; 1-5 estaminódios; ovário séssil, estilete curvado, estigma terminal. Fruto legume, elasticamente deiscente.

\section{Chave para as espécies de Chamaecrista}

1. Nectário foliar presente

2. Folhas 4-8-folioladas

3. Estípulas ovado-orbiculares, $14-24 \times 14-19 \mathrm{~mm}$

3. Estípulas lanceoladas, 3-12×1-3 mm

4. Folhas 4-folioladas; estípulas 5-12 mm compr.

2.7. C. rotundata var. grandistipula

4. Folhas 6-8-folioladas; estípulas 3-4 mm compr.

2.2. C. desvauxii var. langsdorfii

2. Folhas 32-36-folioladas

2.4. C. mucronata

Nectário foliar ausente

5. Ramos revestidos por tricomas glandulares

6. Folhas 2-4-folioladas; folíolos lanceolados, falcados, margem serrada

2.1. C. dentata

6. Folhas 8-18-folioladas; folíolos elípticos, margem inteira

7. Folhas 8-12-folioladas; folíolos 2,3-3 cm compr., margem sem tricomas glandulares

2.3. C. hedysaroides

7. Folhas 16-18-folioladas; folíolos 0,7-0,9 cm compr., margem com tricomas glandulares esparsos

2.5. C. multipennis

5. Ramos hirsutos ou glabros

8. Ervas prostradas; folhas 2-folioladas; folíolos ovados, 0,8-1,4 cm compr.

2.8. C. rotundifolia var. rotundifolia

8. Arbustos; folhas 4-folioladas; folíolos elípticos, 4,7-5,7 cm compr. ... 2.6. C. ochnacea var. ochnacea 
2.1. Chamaecrista dentata (Vogel) H.S. Irwin \& Barneby, Mem. New York Bot. Gard. 35: 658. 1982. Cassia dentata Vogel, Gen. Cass. Syn. 49. 1837.

Fig. 5-7

Arbustos 2,5-4 m alt., ramos cilíndricos, delgados, revestidos por tricomas glandulares. Folhas 2-4folioladas, pêndulas; estípulas 1,5-4 mm compr., filiformes; folíolos 3,7-7,5×0,9-2 cm, lanceolados, falcados, margem serrada, revestidos por tricomas glandulares; nectário foliar ausente. Inflorescência pluriflora, axilar; sépalas 1,7-2 cm compr., avermelhadas, com tricomas glandulares externamente; pétalas 5, 4 externas ca. $2 \mathrm{~cm}$ compr., subiguais, 1 vexilar interna 1,6-1,8 cm compr., cuculada; estames 10 , 4-7 mm compr., anteras 3-6 mm compr.; ovário ca. $4 \mathrm{~mm}$ compr., revestido por tricomas glandulares, estilete 1,3-1,4 cm compr., glabro. Legume 3,9-4,5× 0,7-0,8 cm, revestido por tricomas glandulares; 4-5 sementes, 5-6 mm compr., obovadas, negras.

Material examinado: BRASIL. Minas Gerais: Ouro Preto, estrada nova do Itacolomi, 9/IV/1974, fl., Lisboa s.n. (OUPR 17849); PEI, Calais, 1/XI/2003, fl. fr., Dutra et al. 145 (VIC); 1/XI/2003, fl. fr., Dutra et al. 147 (VIC); 20/I/2004, fl., Dutra et al. 163 (VIC).

Apresenta distribuição geográfica restrita à Serra do Cipó e à Serra do Itacolomi, ocorrendo em solos arenosos entre 1.000-1.300 m (Irwin \& Barneby 1978). No PEI foi encontrada no Morro do Cachorro e Calais, em áreas de escrube sobre filito e quartzito, respectivamente, e com declividade acentuada.

Floração e frutificação: de janeiro a dezembro.

É uma espécie facilmente reconhecida por apresentar o caule delgado e as folhas pêndulas, com a superfície brilhante e margem serrada, características que a diferenciam das demais espécies de Caesalpinioideae do PEI. As populações desta espécie são facilmente avistadas na área do Parque, principalmente no inverno, quando seus folíolos tomam uma coloração avermelhada. A espécie encontra-se em perigo de extinção devido à restrita área de distribuição (Mendonça \& Lins 2000).

2.2. Chamaecrista desvauxii (Collad.) Killip var. langsdorfii (Kunth ex Vogel) H.S. Irwin \& Barneby, Mem. New York Bot. Gard. 35: 879. 1982.

Cassia langsdorfii Kunth ex Vogel, Gen. Cass. Syn. 55.1837.

Fig. 8-10

Arbustos 0,5-1 m alt., ramos cilíndricos, puberulentos. Folhas 4-folioladas; estípulas 5-12x
1-3 mm, lanceoladas; folíolos 8-22×2-5 mm, oblongos a elípticos, margem inteira, glabros; nectário foliar pateliforme, localizado no pecíolo. Flor solitária, axilar; sépalas 8-9 mm compr., verdes, seríceas a glabras externamente; pétalas 5, 1-1,2 cm compr., subiguais; estames 10, 4-9 mm compr., anteras 4-8 mm compr.; ovário 6-8 mm compr., velutino, estilete ca. $2 \mathrm{~mm}$ compr., glabro. Legume 3,4-4×0,5-0,6 cm, seríceo; 14-15 sementes, 4-5×1-2 mm, oblongas, castanhas.

Material examinado: BRASIL. Minas Gerais: PEI, Ouro Preto, Calais, 5/XII/2003, fl. fr., Dutra et al. 176 (VIC); 18/III/2004, fr., Dutra \& Garcia 200 (VIC); 17/VI/2004, fl. fr., Dutra \& Pereira 240 (VIC).

Ocorre amplamente no Brasil, principalmente na Chapada dos Veadeiros (GO), na Cadeia do Espinhaço (MG) e nos estados de São Paulo, Paraná e Mato Grosso. Habita cerrado e campo, às vezes afloramentos (Irwin \& Barneby 1982). No PEI foi coletada no Calais, em campos graminosos secos e observada na Estrada de Cima, em áreas de escrube sobre filito.

Floração: de dezembro a março e em junho. Frutificação: de dezembro a junho.

O táxon no PEI pode ser diferenciado dos demais pelas folhas com a raque curta, folíolos estreitos e anteras negras. Os nectários foliares, importantes no reconhecimento da variedade, são de difícil visualização, pois são caducos e, nas folhas jovens ficam ocultos pelo pecíolo canaliculado.

2.3. Chamaecrista hedysaroides (Vogel) H.S. Irwin \& Barneby, Mem. New York Bot. Gard. 35: 656. 1982.

Cassia hedysaroides Vogel, Gen. Cass. Syn. 52. 1837. Fig. 11-12

Arbustos 1,8-2 m alt., ramos cilíndricos, revestidos por tricomas glandulares. Folhas 8-12-folioladas; estípulas ca. $1 \mathrm{~mm}$ compr., lanceoladas; folíolos 2,3-3×1,1-1,5 cm, oblongos, margem inteira, face abaxial glabra, face adaxial revestida por tricomas glandulares; nectário foliar ausente. Inflorescência pluriflora, axilar; sépalas 12-13×4-5 mm, verdes, revestidas por tricomas glandulares externamente; pétalas 5, 4 externas 1,2-1,5 cm compr., subiguais, 1 vexilar interna ca. $1,4 \mathrm{~cm}$ compr., cuculada; estames 10, 4,5-5 mm compr., anteras 3-4 mm compr.; ovário ca. $3 \mathrm{~mm}$ compr., revestido por tricomas glandulares, estilete ca. 1,4 cm compr., glabro. Legume 3,5-5x 0,8-1 cm, viscoso; 4-7 sementes, 4-6×3-4 mm, obovadas, negras.

Material examinado: BRASIL. Minas Gerais: PEI, Mariana, Serrinha, 14/IV/2004, fl. fr., Dutra \& 
Garcia 219 (VIC); 4/VIII/2004, fr., Dutra et al. 260 (VIC); 4/VIII/2004, fr., Dutra et al. 261 (VIC).

Restrita à Minas Gerais, sendo encontrada em Diamantina, Serro, Santo Antônio, Ouro Preto e na Serra do Caraça, em afloramentos ou penhascos, solos arenosos ou cascalhosos, ao longo de rios, ocasionalmente em cerrado ou margens de matas, entre 1.050-1.400 m (Irwin \& Barneby 1978). No PEI ocorre apenas na região da Serrinha, em área de campo graminoso úmido, formando uma população pequena próximo à trilha da captação de água.

Floração: abril. Frutificação: de abril a agosto.

Caracteriza-se pelas estípulas inconspícuas (ca. $1 \mathrm{~mm}$ compr.), completa supressão de tricomas tectores nos ramos e folhas e pelos folíolos oliváceos e com a superfície adaxial pontilhada por uma resina negra, quando secos.

2.4. Chamaecrista mucronata (Spreng.) H.S. Irwin \& Barneby, Mem. New York Bot. Gard. 35: 684. 1982. Cassia mucronata Spreng., Syst. Veg. 2: 341. 1825.

Fig. 13-15

Arbustos 0,8-1 m alt., ramos estriados, hirsutos. Folhas 6-8-folioladas; estípulas 3-4×1 mm, lanceoladas; folíolos 1,2-2,4×0,6-1,1 cm, ovados a oblongos, margem inteira, glabros; nectário foliar pateliforme, localizado no pecíolo. Inflorescência 1-2-flora, axilar; sépalas 1,2-1,4 cm compr., amarelas, puberulentas a glabras externamente; pétalas 5, 4 externas ca. $2 \mathrm{~cm}$ compr., subiguais, 1 vexilar interna 2-2,6 cm compr., encurvada; estames 10, 6-9 mm compr., anteras 5-8 mm compr.; ovário ca. $5 \mathrm{~mm}$ compr., puberulento, estilete ca. $5 \mathrm{~mm}$ compr., glabro. Legume 5,8-6,7×0,6-0,8 cm, glabro; 5-12 sementes, 4-5×3-4 mm, obovadas, castanhas.

Material examinado: BRASIL. Minas Gerais: PEI, Ouro Preto, Baú, 19/II/1994, fl. fr., Roschel s.n. (VIC 28463, OUPR 1349); Estrada de Cima, 30/IX/2003, fl. fr., Dutra et al. 138 (VIC); Morro do Cachorro, 29/III/2004, fl., Dutra et al. 208 (VIC); Calais, 17/VI/2004, fl., Dutra \& Pereira 241 (VIC).

Espécie restrita à Cadeia do Espinhaço, ocorrendo em afloramentos de xisto e canga, entre 1.150-1.600 m (Irwin \& Barneby 1982). Nos campos rupestres do PEI pode ser encontrada no Morro do Cachorro e no início das Estradas de Cima e de Baixo, em áreas de escrube sobre filito; no Calais, em campos graminosos secos e campos quartizíticos dos afloramentos rochosos e, no Baú, em campos quartzíticos dos afloramentos rochosos.

Floração: de agosto a junho. Frutificação: de setembro a março.
A espécie pode ser facilmente reconhecida por apresentar-se bem ramificada, formando um arbusto denso e com a porção distal dos ramos levemente reflexos.

\subsection{Chamaecrista multipennis (H.S. Irwin \&} Barneby) H.S. Irwin \& Barneby, Mem. New York Bot. Gard. 35: 654. 1982.

Cassia multipennis H.S. Irwin \& Barneby, Mem. New York Bot. Gard. 30: 125-127. 1978.

Fig. 16-18

Arbustos ca. 1,5 m alt., ramos cilíndricos, revestidos por tricomas glandulares. Folhas 16-18-folioladas; estípulas 1-3 mm compr., lanceoladas; folíolos 7-9x 4-5 mm, elípticos, margem inteira, com tricomas glandulares esparsos; nectário foliar ausente. Inflorescência pluriflora, axilar ou terminal; sépalas 9-12 mm compr., avermelhadas, revestidas por tricomas glandulares externamente; pétalas 5, 4 externas 1-1,2 cm compr., subiguais, 1 vexilar interna 1-1,1 cm compr., encurvada; estames 10, 4-5 mm compr., anteras 3-4 mm compr.; ovário 2-3 mm compr., tomentoso, estilete ca. $1 \mathrm{~cm}$ compr., glabro. Legume não observado.

Material examinado: BRASIL. Minas Gerais: PEI, Mariana, Serrinha, II/2006, fl., Silva s.n. (VIC 30740).

Ocorre no sul da Cadeia do Espinhaço e na Serra de São José, em afloramentos rochosos (Irwin \& Barneby 1978). No PEI foi encontrada apenas na Serrinha, em pequena população sobre campo graminoso úmido.

Floração: fevereiro.

Entre as Caesalpinioideae do PEI, é a única espécie que apresenta a margem dos folíolos com tricomas glandulares. Pode ser confundida com $C$. cipoana (H.S. Irwin \& Barneby) H.S. Irwin \& Barneby, com a qual é simpátrica nos Campos Rupestres da região, e que apresenta folhagem glauca, folíolos com margem ciliada e sépalas argênteo-pilosas.

2.6. Chamaecrista ochnacea (Vogel) H.S. Irwin \& Barneby var. ochnacea, Mem. New York Bot. Gard. 35: 656. 1982.

Cassia ochnacea Vogel, Generis Cassiae Synopsis 51. 1837.

Fig. 19

Arbustos ca. $1 \mathrm{~m}$ alt., ramos estriados, glabros. Folhas 4-folioladas; estípulas 5-7 mm compr., filiformes; folíolos 4,7-5,7×1,5-2 cm, elípticos, margem inteira, vinácea, glabros; nectário foliar ausente. 


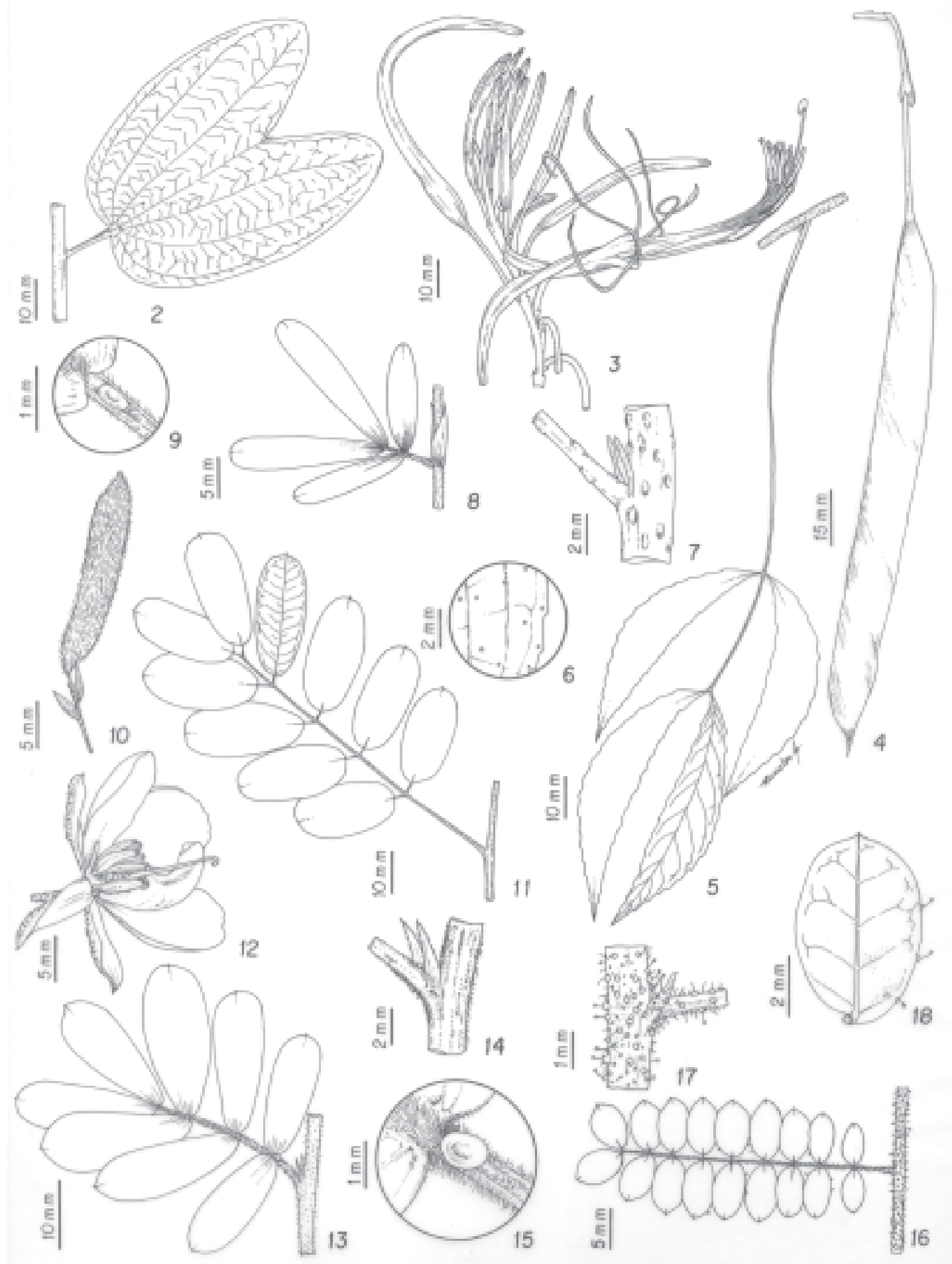

Figuras 2-4. Bauhinia ungulata var. cuiabensis (Bong.) Vaz. 2. Folha. 3. Inflorescência (Dutra \& Garcia 217). 4. Legume (Dutra et al. 263). Figuras 5-7. Chamaecrista dentata (Vogel) H.S. Irwin \& Barneby. 5. Folha. 6. Detalhe do indumento dos folíolos. 7. Detalhe da estípula (Dutra et al. 147). Figuras 8-10. C. desvauxii (Collad.) Killip var. langsdorfii (Kunth ex Vogel) H.S. Irwin \& Barneby. 8. Folha e estípulas. 9. Detalhe do nectário foliar. 10. Legume (Dutra et al. 176). Figuras 11-12. C. hedysaroides (Vogel) H.S. Irwin \& Barneby. 11. Folha. 12. Flor sem uma das pétalas para visualizar a pétala vexilar interna diferenciada em tubo (Dutra \& Garcia 219). Figuras 13-15. C. mucronata (Spreng.) H.S. Irwin \& Barneby. 13. Folha. 14. Detalhe das estípulas. 15. Detalhe do nectário foliar (Dutra et al. 138). Figuras 16-18. C. multipennis (H.S. Irwin \& Barneby) H.S. Irwin \& Barneby. 16. Folha. 17. Detalhe da estípula. 18. Detalhe da margem do folíolo (Silva s.n. VIC30740). 
Inflorescência pluriflora, terminal; sépalas 9-10 mm compr., amarelo-esverdeadas, vilosas externamente; pétalas 5, 4 externas 1,3-1,6 cm compr., subiguais, 1 vexilar interna ca. $1,5 \mathrm{~cm}$ compr., encurvada; estames 10, 4-6 mm compr., anteras 3-4 mm compr.; ovário ca. $3 \mathrm{~mm}$ compr., tomentoso, estilete $9-10 \mathrm{~mm}$ compr., esparso-tomentoso. Legume 4-4,4×0,7 cm, tomentoso; sementes não observadas.

Material examinado: BRASIL. Minas Gerais: PEI, Ouro Preto, Baú, Lagoa Seca, II/2006, fl. fr., Messias et al. 917 (OUPR, VIC).

Apresenta distribuição restrita à Cadeia do Espinhaço, ocorrendo em Nova Lima, Serras de Ouro Branco, de Santo Antônio (Irwin \& Barneby 1978), do Itambé e do Caraça (Bentham 1870). No PEI foi encontrada apenas no Baú, em afloramento rochoso.

Floração e frutificação: fevereiro.

É facilmente reconhecida por apresentar uma longa inflorescência pluriflora, terminal e folíolos com as margens vináceas. Pode ser confundida com C. ochnacea var. purpurascens, que também ocorre nos Campos Rupestres da Cadeia do Espinhaço, diferindo pelos folíolos glabros em ambas as faces, pétalas amarelas e legume tomentoso.

2.7. Chamaecrista rotundata (Vogel) H.S. Irwin \& Barneby var. grandistipula (Vogel) H.S. Irwin \& Barneby, Mem. New York Bot. Gard. 35: 676. 1982.

Cassia grandistipula Vogel, Gen. Cass. Syn. 58-59. 1837.

Fig. 20-21

Arbustos 1,5-2 m alt., ramos cilíndricos, puberulentos. Folhas 6-8-folioladas; estípulas 1,4-2,4×1,4-1,9 cm, ovado-orbiculares; folíolos 1,3-2×0,7-1,2 cm, oblongos, margem inteira, glabros; nectário foliar pateliforme, localizado no pecíolo. Flor solitária, axilar; sépalas 1,6-2,1×0,6-0,7 cm, avermelhadas, glabras externamente; pétalas 5,4 externas ca. 2,6 cm compr., subiguais, 1 vexilar interna 3-3,1 cm compr., encurvada; estames 10, 0,8-1,1 cm compr., anteras 0,7-1 cm compr.; ovário ca. $1,1 \mathrm{~cm}$ compr., velutino, estilete ca. 1,2 cm compr., glabro. Legume 5,4-7,5×1-1,1 cm, velutino quando jovem, glabro quando maduro; 9-10 sementes, 5-6×3 mm, oblongas, negras.

Material examinado: BRASIL. Minas Gerais: PEI, Ouro Preto, Morro do Cachorro, próximo à torre da Embratel, 13/IV/2004, fl., Dutra \& Garcia 214 (VIC); 3/VIII/2004, fr., Dutra et al. 257 (VIC); 3/VIII/2004, fr., Dutra et al. 258 (VIC); Calais,
17/VI/2004, fl. fr., Dutra \& Pereira 239 (VIC).

Ocorre na Cadeia do Espinhaço, em Diamantina e Ouro Preto, nos Campos Rupestres (Irwin \& Barneby 1982). É uma espécie bastante rara no PEI, onde forma pequenas populações sobre campos quartzíticos dos afloramentos rochosos, no Calais e no Morro do Cachorro.

Floração: de abril a junho. Frutificação: de abril a agosto.

Pode ser reconhecido, entre as Caesalpinioideae do PEI, por ser o único táxon que apresenta amplas estípulas persistentes, ovado-orbiculares e com as margens amareladas, quando jovens.

2.8. Chamaecrista rotundifolia (Pers.) Greene var. rotundifolia, Pittonia 4: 31. 1899.

Cassia rotundifolia Pers., Syn. Pl. 1: 456. 1805.

Ervas prostradas, ramos cilíndricos, hirsutos, puberulentos. Folhas 2-folioladas; estípulas 4-6x 1-3 mm, lanceoladas; folíolos 8-14×6-9 mm, ovados, assimétricos, margem inteira, face abaxial esparsotomentosa, face adaxial glabra; nectário foliar ausente. Flor solitária, axilar; sépalas $5 \times 2 \mathrm{~mm}$, verdes, seríceas externamente; pétalas 5, 5-6 mm compr., subiguais; estames 5, 3-4 mm compr., anteras 2-3 mm compr.; estaminódios 2; ovário ca. $3 \mathrm{~mm}$ compr., velutino, estilete ca. 2 mm compr., glabro. Legume 2,2-2,6x $0,4 \mathrm{~cm}$, puberulento; $9-10$ sementes, $3 \times 2 \mathrm{~mm}$, oblongas, castanhas.

Material examinado: BRASIL. Minas Gerais: PEI, Ouro Preto, estrada para Morro do Cachorro, próximo à Capela, 18/III/2004, fl. fr., Dutra \& Garcia 190 (VIC).

Estende-se dos Estados Unidos e México até o Uruguai e Argentina, em cerrados, campos, estradas, matas perturbadas, pastagens, locais abertos e iluminados (Irwin \& Barneby 1982). No PEI foi coletada na estrada para o Morro do Cachorro, próximo à Capela, em campo ferruginoso, e observada na Serrinha, em campo graminoso úmido.

Floração e frutificação: de janeiro a março.

As pequenas flores com androceu pentâmero e dois estaminódios são características exclusivas de C. rotundifolia var. rotundifolia entre as Caesalpinioideae do PEI. É ocasionalmente confundida com a espécie simpátrica na região, $C$. diphylla (L.) Greene, pela semelhança no número e forma dos folíolos. Entretanto, difere desta espécie principalmente pelo androceu pentâmero e por não apresentar nectário foliar (Irwin \& Barneby 1982). 
2.9. Chamaecrista trichopoda (Benth.) Britton \& Rose ex Britton \& Killip, Ann. New York Acad. Sci. 35(3): 185. 1936.

Cassia trichopoda Benth., Fl. Bras. 15(2): 163. 1870.

Ervas ca. $50 \mathrm{~cm}$ alt., ramos cilíndricos, hirsutos. Folhas 32-36-folioladas; estípulas 7-9×1 mm, lanceoladas; folíolos 1,1-1,3×0,2 cm, oblongos, margem inteira, face abaxial serícea a glabra, face adaxial glabra; nectário foliar caliciforme, localizado no pecíolo. Inflorescência 1-2-flora, axilar; sépalas ca. $8 \mathrm{~mm}$ compr., amarelas, seríceas externamente; pétalas 5, 6-10 mm compr., subiguais; estames 10, 4-7 mm compr., anteras 3-6 mm compr.; ovário ca. $7 \mathrm{~mm}$ compr., tomentoso, estilete ca. $4 \mathrm{~mm}$ compr., glabro. Legume 5,1-6,4×0,3-0,4 cm, seríceo; 19-20 sementes, 2-3×2 mm, oblongas, castanhas.

Material examinado: BRASIL. Minas Gerais: PEI, Ouro Preto, estrada de baixo, próximo ao estacionamento, na entrada do Parque, 18/III/2004, fl. fr., Dutra \& Garcia 196 (VIC).

Ocorre na Bolívia, Venezuela, Colômbia e Brasil, em Goiás, Mato Grosso, Minas Gerais e São Paulo, estendendo-se até o Pará e Maranhão, sendo encontrada em cerrado, campo, pastagem e margem de mata de galeria (Irwin \& Barneby 1982). No PEI foi coletada próximo à portaria do Parque, em área alterada, em escrube sobre filito, e sua ocorrência observada no Calais, em campos quartzíticos dos afloramentos rochosos.

Floração e frutificação: março.

Caracteriza-se pelas folhas com numerosos pares de folíolos e pelos nectários foliares caliciformes.

\section{Senna Mill., Gard. Dict. Abr., ed. 4, vol. 3. 1754.}

Subarbustos, arbustos, eretos a escandentes, árvores ou lianas. Folhas paripinadas, 2-plurifolioladas; estípulas decíduas, raro persistentes ou tardiamente caducas; nectário foliar, quando presente, secretando néctar em uma superfície convexa. Inflorescência racemosa ou paniculada, axilar ou terminal; flores 5-meras, zigomorfas; cálice dialissépalo; corola amarela; estames 6-7, heteromórficos, em dois grupos, sendo 4 estames medianos dispostos aos pares e 2-3 estames abaxiais, maiores que os demais, retos ou curvados, 3-4 estaminódios adaxiais, filetes livres, anteras poricidas ou curto-rimosas; ovário séssil, estilete curvado, estigma terminal. Fruto legume, com deiscência passiva ou indeiscente.
Chave para as espécies de Senna

1. Nectário foliar localizado no pecíolo; estípulas filiformes ou lanceoladas, 3-11 mm compr.

2. Nectário foliar claviforme; legume subcilíndrico .... 3.2. S. pendula var. glabrata

2. Nectário foliar globoso; legume plano-compresso.

3.1. S. neglecta var. oligophylla

1. Nectários foliares localizados entre os folíolos; estípulas reniformes, 15-34 mm compr. 3.3. S. reniformis

3.1. Senna neglecta (Vogel) H.S. Irwin \& Barneby var. oligophylla (Benth.) H.S. Irwin \& Barneby, Mem. New York Bot. Gard. 35: 424. 1982.

Cassia oblongifolia var. oligophylla Benth., Fl. Bras. 15(2): 111. 1870.

Fig. 22-23

Arbustos ca. $3 \mathrm{~m}$ alt., ramos estriados, tomentosos. Folhas 6-8-folioladas; estípulas ca. 3mm compr., lanceoladas; folíolos 1,5-4,7×0,9-2 cm, elípticos a obovados, margem inteira, glabros; nectário foliar globoso, localizado no pecíolo. Inflorescência racemosa, 22-25flora, axilar; sépalas 7-9 mm compr., amarelas, setosas externamente; pétala centro-adaxial ca. $15 \mathrm{~mm}$ compr.; estames maiores 2, 1,2-1,4 cm compr., anteras 4-5 mm compr., estames menores 4, 5-6 mm compr., anteras 4-5 mm compr.; estaminódios 4; ovário 4-5 mm compr., tomentoso, estilete 4-5 $\mathrm{mm}$ compr., glabro. Legume plano-compresso, 24-25×1 cm, glabro, deiscente; 29-30 sementes, 5-6×3-4 mm, obovadas, negras.

Material examinado: BRASIL. Minas Gerais: PEI, Ouro Preto, Baú, Lagoa Seca, 30/I/2006, fl. fr., Messias 1003 (OUPR, VIC).

É citada para a Serra dos Órgãos, no Rio de Janeiro, e para as Serras do Caraça e Ibitipoca, em Minas Gerais (Irwin \& Barneby 1982). Habita matas e escarpas associadas a afloramentos rochosos, entre 1.100-1.850 m (Irwin \& Barneby 1982). No PEI ocorre apenas no Baú, próximo à Lagoa Seca, em pequena população, sobre afloramento rochoso.

Floração e frutificação: janeiro.

Apresenta seis estames e quatro estaminódios, e um amplo legume, que pode chegar a $25 \mathrm{~cm}$ de comprimento, características que a diferenciam das demais Caesalpinioideae do PEI. 

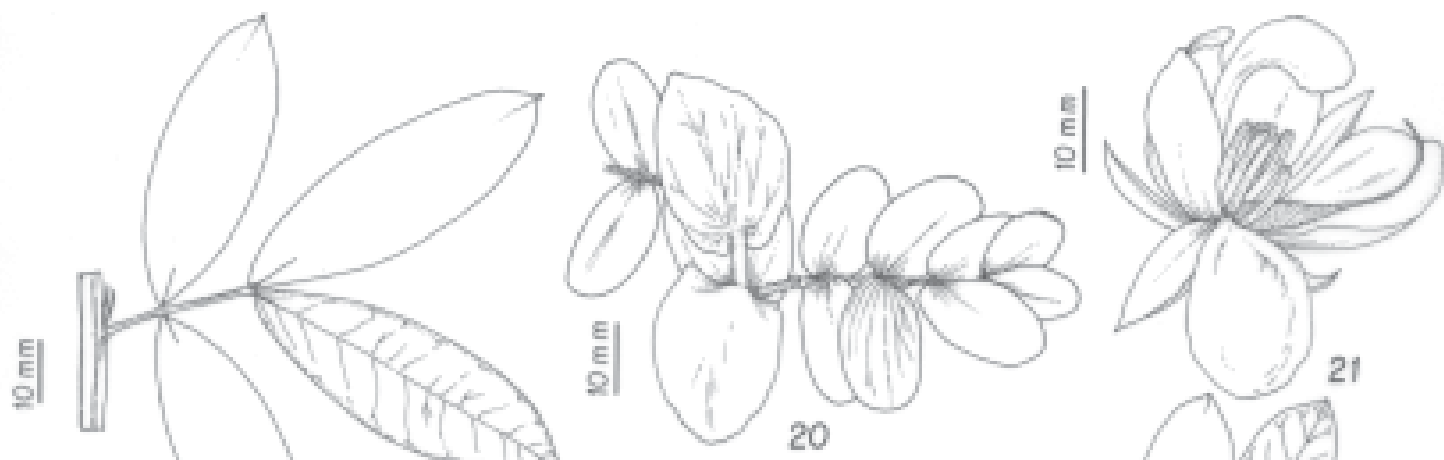

19
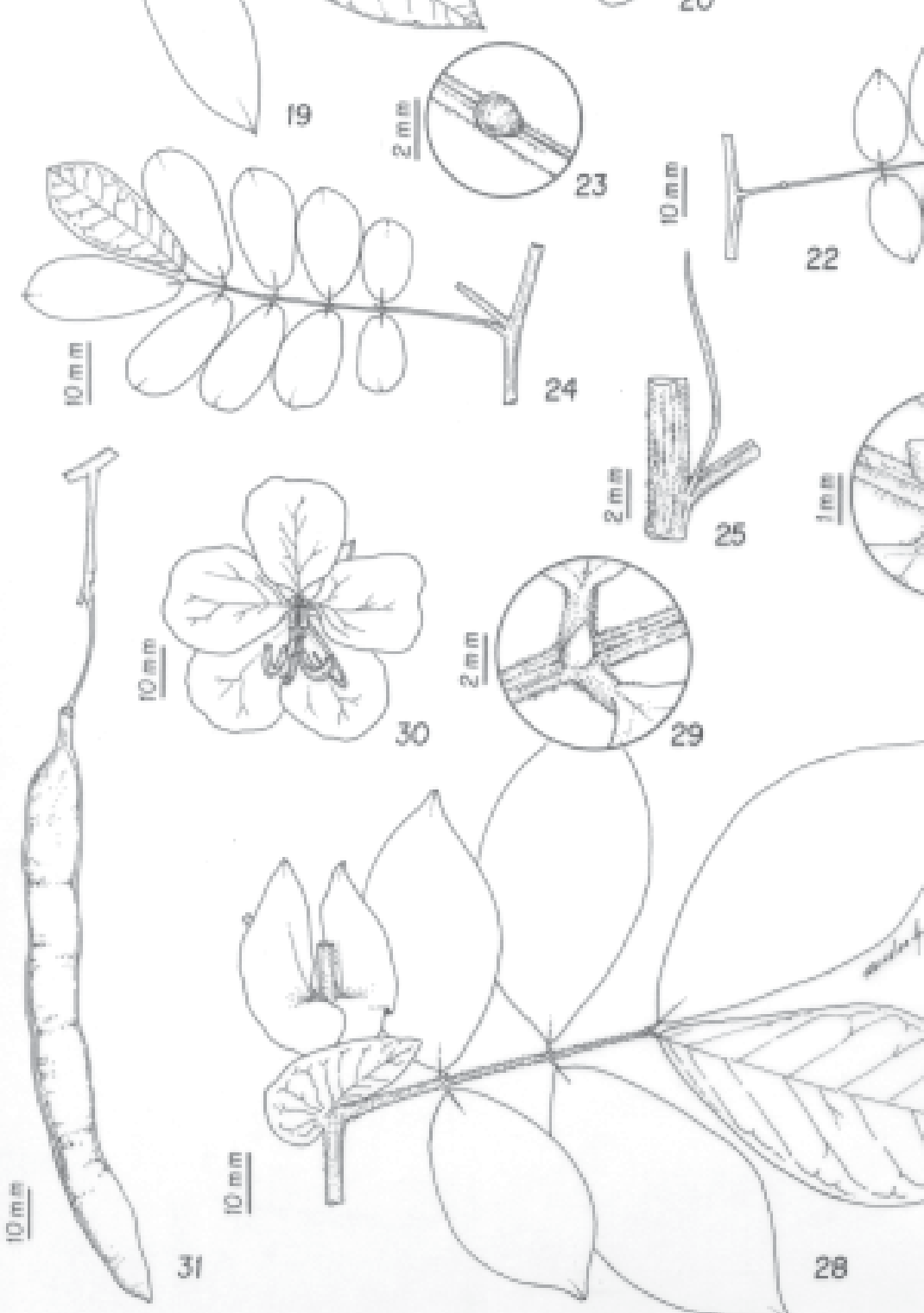

을

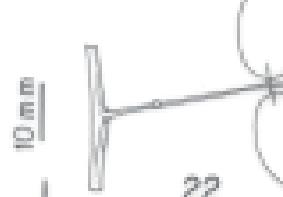

22

21

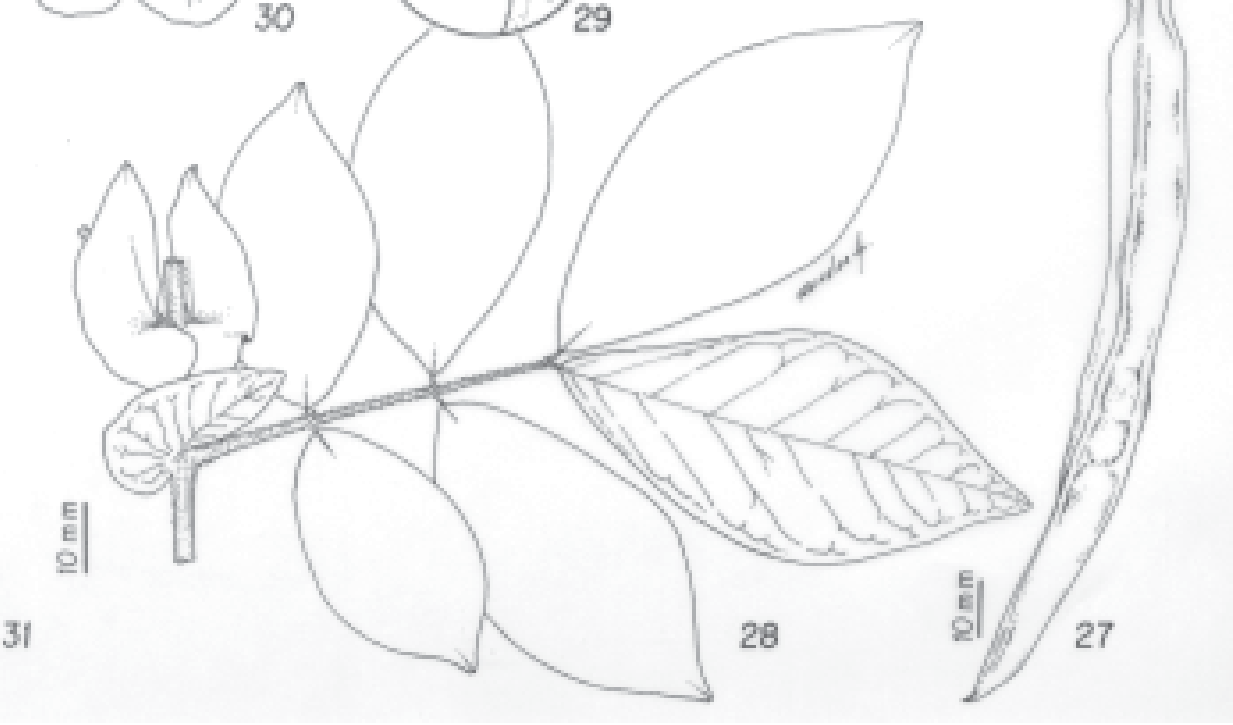

Figura 19. Chamaecrista ochnacea (Vogel) H.S. Irwin \& Barneby var. ochnacea. 19. Folha (Messias et al. 917). Figuras 20-21. C. rotundata (Vogel) H.S. Irwin \& Barneby var. grandistipula (Vogel) H.S. Irwin \& Barneby. 20. Folha e estípulas (Dutra \& Pereira 239). 21. Flor sem uma das pétalas para visualizar a pétala interna encurvada (Dutra \& Garcia 214). Figuras 22-23. Senna neglecta (Vogel) H.S. Irwin \& Barneby var. oligophylla (Benth.) H.S. Irwin \& Barneby. 22. Folha. 23. Detalhe do nectário foliar (Messias 1003). Figuras 24-27. S. pendula (Willd.) H.S. Irwin \& Barneby var. glabrata (Vogel) H.S. Irwin \& Barneby. 24. Folha. 25. Detalhe da estípula. 26. Detalhe do nectário foliar (Dutra \& Garcia 180). 27. Legume (Dutra \& Pereira 212). Figuras 28-31. S. reniformis (G. Don) H.S. Irwin \& Barneby. 28. Folha e estípulas. 29. Detalhe do nectário foliar (Dutra et al. 150). 30. Flor (Dutra et al. 183). 31. Legume (Dutra et al. 129). 
3.2. Senna pendula (Willd.) H.S. Irwin \& Barneby var. glabrata (Vogel) H.S. Irwin \& Barneby, Mem. New York Bot. Gard. 35: 382. 1982.

Cassia indecora var. glabrata Vogel, Gen. Cass. Syn. 19. 1837.

Fig. 24-27

Arbustos 1,5-2 m alt., ramos estriados, tomentosos. Folhas 8-12-folioladas; estípulas 0,9-1,1 cm compr., filiformes; folíolos 2-2,4×1-1,3 cm, obovados, margem inteira, glabros; nectário foliar claviforme, localizado no pecíolo. Inflorescência racemosa, 3-8-flora, axilar; sépalas ca. 1,5 cm compr., amarelas, glabras externamente; pétala centro-adaxial 2,1-2,3 cm compr.; estames maiores 3, 1,5-3,4 cm compr., anteras 0,9-1,1 cm compr., estames menores 4 , ca. $9 \mathrm{~mm}$ compr., anteras ca. $7 \mathrm{~mm}$ compr.; estaminódios 3; ovário ca. $2,4 \mathrm{~cm}$ compr., puberulento, estilete ca. $2 \mathrm{~mm}$ compr., glabro. Legume subcilíndrico, 12,4-17x $1-1,3 \mathrm{~cm}$, glabro, indeiscente; $32-54$ sementes, bisseriadas, $5 \times 3-4 \mathrm{~mm}$, elípticas, negras.

Material examinado: BRASIL. Minas Gerais: PEI, Ouro Preto, estrada para Morro do Cachorro, próximo à Fazenda do Manso, 16/III/2004, fl., Dutra \& Garcia 180 (VIC); estrada para Morro do Cachorro, 17/III/2004, fl., Dutra et al. 186 (VIC); Calais, 17/VI/2004, fr., Dutra \& Pereira 212 (VIC). Mariana, Serrinha, 4/VIII/2004, fr., Dutra et al. 254 (VIC).

Está amplamente distribuída no planalto brasileiro, atingindo o Mato Grosso, Bahia, São Paulo, Paraná e Santa Catarina (Bortoluzzi 2004). Ocorre em cerrado, cerradão, margem de mata de galeria, estendendo-se até os campos rupestres entre 1.320-2.000 m, na Cadeia do Espinhaço (Irwin \& Barneby 1982). No PEI ocorre na Serrinha, em campo graminoso úmido; no Calais, em campo graminoso seco; e na estrada para o Morro do Cachorro, em escrube sobre filito.

Floração: de março a maio. Frutificação: de junho a agosto.

Os principais caracteres diagnósticos de S. pendula var. glabrata são as estípulas filiformes, as inflorescências 3-8-floras e, principalmente, os frutos subcilíndricos, com sementes bisseriadas.

\subsection{Senna reniformis (G.Don) H.S. Irwin \& Barneby,}

Mem. New York Bot. Gard. 35: 223. 1982.

Cassia reniformis G.Don, Gen. Hist. 2: 440. 1832.

Fig. 28-31

Arbustos 1,5-4 m alt., ramos estriados, ferrugíneotomentosos. Folhas 6-8-folioladas; estípulas 1,5-3,4×0,9-2 cm, foliáceas, reniformes; folíolos 3-7×1,8-3,4 cm, elípticos a obovados, face abaxial esparso-tomentosa a glabra, com tricomas glandulares, face adaxial glabra; nectários foliares piriformes, entre os folíolos de todos os pares. Inflorescência racemosa, pluriflora, axilar ou terminal; sépalas ca. 1,6 cm compr., amarelas, puberulentas externamente; pétala centroadaxial 2,6-3 cm compr.; estames maiores 3, 1,6-2 cm compr., anteras 0,6-1 cm compr., estames menores 4 , ca. $9 \mathrm{~mm}$ compr., anteras ca. $5 \mathrm{~mm}$ compr.; estaminódios 3; ovário ca. 1,8 cm compr., puberulento, estilete ca. $8 \mathrm{~mm}$ compr., glabro. Legume planocompresso, 9-13,4×1-1,4 cm, glabro, deiscente; 26-28 sementes, ca. $6 \mathrm{~mm}$ compr., oblongas, negras.

Material examinado: BRASIL. Minas Gerais: PEI, Ouro Preto, Baú, 29/IX/2003, fr., Dutra et al. 129 (VIC); 16/III/2004, fl., Dutra et al. 183 (VIC); Calais, 9/XII/2003, fl., Dutra et al. 150 (VIC). Mariana, Sertão, 14/IV/2004, fl. fr., Dutra \& Garcia 228 (VIC).

Ocorre em Minas Gerais e na Bahia, sendo endêmica da Cadeia do Espinhaço, habitando áreas de cerrado, margens de mata de galeria, brejos, afloramentos rochosos, comumente em solo quartzítico e canga, em altitudes entre 950-1.800 m (Irwin \& Barneby 1982). No PEI encontra-se amplamente distribuída, ocorrendo em quatro das oito trilhas percorridas: no Calais, em escrubes sobre filito; no Baú, em escrubes sobre quartzito; no Sertão, em campos quartzíticos dos afloramentos rochosos; e, no Tesoureiro, sobre campos ferruginosos, sendo uma das poucas espécies de Leguminosae que ocorre nas três últimas trilhas.

Floração: de dezembro a maio. Frutificação: de janeiro a setembro.

Senna reniformis é facilmente diagnosticada por ser a única espécie entre as Caesalpinioideae do PEI que apresenta estípulas foliáceas e reniformes. Pode ser confundida com S. cana (Ness \& C. Mart.) H.S. Irwin \& Barneby, espécie simpátrica na região, por esta apresentar estípulas semelhantes. No entanto, em S. cana os nectários localizam-se na base do pecíolo e o fruto é mais estreito e tetragonal.

Entre os táxons encontrados nos Campos Rupestres do Parque Estadual do Itacolomi, dez são novas citações para a flora do Parque, Bauhinia ungulata var. cuiabensis, Chamaecrista desvauxii var. langsdorfii, C. hedysaroides, C. multipennis, C. ochnacea var. ochnacea, C. rotundata var. grandistipula, C. rotundifolia var. rotundifolia, C. trichopoda, Senna neglecta var. oligophylla e S. pendula var. glabrata. Seis táxons são endêmicos da Cadeia do Espinhaço, Chamaecrista dentata, 
C. hedysaroides, C. mucronata, C. ochnacea var. ochnacea, C. rotundata var. grandistipula e Senna reniformis.

Chamaecrista dentata, C. hedysaroides, C. multipennis, C. ochnacea var. ochnacea C. rotundata var. grandistipula e Senna neglecta var. oligophylla ocorrem, muitas vezes, em populações pequenas e/ou restritas a determinados hábitats, sendo que $C$. dentata encontra-se na lista vermelha das espécies em extinção (Mendonça \& Lins 2000), indicando a importância da conservação dos Campos Rupestres e da flora deste Parque.

\section{Agradecimentos}

Os autores agradecem ao Eng. Alberto Vieira de Mello Matos, Diretor do Parque Estadual do Itacolomi, e aos funcionários do PEI, pelo auxílio; ao Instituto Estadual de Florestas (IEF), pela autorização de coleta concedida; aos curadores dos herbários visitados, OUPR, RB e HUEFS; ao Jorge Luiz Silva, pelo auxílio nos trabalhos de campo; e ao Reinaldo Pinto, pela elaboração das ilustrações.

\section{Referências bibliográficas}

Barroso, G.M.; Morim, M.P.; Peixoto, A.L. \& Ichaso, C.L.F. 1999. Frutos e sementes: morfologia aplicada à sistemática de dicotiledôneas. Viçosa, Imprensa Universitária.

Barroso, G.M.; Peixoto, A.L.; Costa, C.G.; Ichasso, C.L.F.; Guimarães, E.F. \& Lima, H.C. 1991. Sistemática das Angiospermas do Brasil. v.2. Viçosa, Imprensa Universitária.

Bentham, G. 1870. Cassia. In: C.F.P. Martius, S. Endlicher \& I. Urban (eds.). Flora Brasiliensis 15: 82-176.

Bortoluzzi, R.L.C. 2004. A subfamília Caesalpinioideae (Leguminosae) no estado de Santa Catarina, Brasil. Tese de Doutorado, Universidade Federal do Rio Grande do Sul.

Chappill, J.A. 1995. Cladistic analysis of the Leguminosae: the development of an explicit phylogenetic hypothesis. Pp. 1-9. In: M. Crisp \& J.J. Doyle (eds.). Advances in Legume Systematics 7: Phylogeny. Kew, Royal Botanic Gardens.

Cowan, R.S. 1981. Caesalpinioideae. Pp. 57-64. In: R.M. Polhill \& P.H. Raven (eds.). Advances in Legume Systematics part I. Kew, Royal Botanic Gardens.

Drummond, G.M.; Martins, C.S.; Machado, A.B.M.; Sebaio, F.A. \& Antonini, Y. 2005. Biodiversidade em Minas Gerais: um atlas para sua conservação. Belo Horizonte, Fundação Biodiversitas.
Dutra, V.F. 2005. Leguminosae Adans. nos Campos Rupestres do Parque Estadual do Itacolomi, Minas Gerais, Brasil: florística, preferência por habitat, aspectos reprodutivos e distribuição geográfica. Dissertação de Mestrado, Universidade Federal de Viçosa.

Dutra, V.F.; Messias, M.C.T.B. \& Garcia, F.C.P. 2005. Papilionoideae (Leguminosae) dos campos ferruginosos do Parque Estadual do Itacolomi, MG, Brasil: florística e fenologia. Revista Brasileira de Botânica 28: 493-504.

Garcia, F.C.P. \& Dutra, V.F. 2004. Leguminosae nos Campos Rupestres. In: CD-ROM. Simpósios, palestras e mesas redondas do $5^{\circ}$ Congresso Nacional de Botânica. Viçosa, Alpha Mídia Assessoria Fonográfica.

Irwin, H.S. \& Barneby, R.C. 1978. Monographic studies in Cassia (Leguminosae-Caesalpinioideae) III. Sections Absus and Grimaldia. Memoirs of The New York Botanical Garden 30: 1-300.

Irwin, H.S. \& Barneby, R.C. 1982. The American CassiinaeA synoptical revision of Leguminosae - Tribe Cassieae subtribe Cassiinae in the New World. Memoirs of The New York Botanical Garden 35: 1-918.

Lewis, G.P. 1987. Legumes of Bahia. Kew, Royal Botanic Gardens.

Lewis, G.P.; Schrire, B.D.; Mackinder, B.A. \& Lock, J.M. 2005. Legumes of the World. Kew, Royal Botanic Gardens.

Lima, L.C.P.; Garcia, F.C.P. \& Sartori, A.L.B. 2007. Leguminosae nas florestas estacionais do Parque Estadual do Itacolomi, Minas Gerais, Brasil: ervas, arbustos, subarbustos, lianas e trepadeiras. Rodriguésia 58: 331-358.

Mendonça, M.P. \& Lins, L.V. 2000. Lista vermelha das espécies ameaçadas de extinção da flora de Minas Gerais. Belo Horizonte, Fundação Biodiversitas, Fundação Zoo-Botânica de Belo Horizonte.

Messias, M.C.T.B.; Dias, S.J.; Roschel, M.B.; Sousa, H.C. \& Matos, A.M. 1997. Levantamento florístico das matas e distribuição de algumas espécies endêmicas da área do Parque Estadual do Itacolomi. Relatório Técnico, UFOP/BIRD/IEF-PROFLORESTA.

Peron, M.V. 1989. Listagem preliminar da flora fanerogâmica dos Campos Rupestres do Parque Estadual do Itacolomi, Ouro Preto/Mariana, MG. Rodriguésia 41: 63-69.

Polhill, R.M. 1994. Classification of the Leguminosae. Pp. 49-57. In: F.A. Bisby; J. Buckingham \& J.B. Harborne (eds.). Phytochemical dictionary of the Leguminosae. New York, Chapman and Hall.

Polhill, R.M. \& Raven, P.H. 1981 (eds.). Advances in Legume Systematics part I. Kew, Royal Botanic Gardens.

Polhill, R.M.; Raven, P.H. \& Stirton, C.H. 1981. Evolution and systematics of the Leguminosae. Pp. 1-26. In: R.M. Polhill \& P.H. Raven (eds.). Advances in Legume Systematics part I. Kew, Royal Botanic Gardens.

Radford, A.E.; Dickison, W.C.; Massey, J.R. \& Bell, C.R. 1974. Vascular Plant Systematics. New York, Harper \& Row.

Vaz, A.M.S.F. \& Tozzi, A.M.G.A. 2003. Bauhinia ser. Cansenia (Leguminosae: Caesalpinioideae) no Brasil. Rodriguésia 54: 55-143. 